\title{
PENGARUH VARIASI KONSENTRASI CAIRAN PENYARI ETANOL TERHADAP KADAR POLIFENOL PADA DAUN BIDURI (Calotropis gigantea L.)
}

\author{
Asriani Suhaenah \\ Fakultas Farmasi Universitas Muslim Indonesia, Makassar \\ Email : asriani.suhaenah@umi.ac.id
}

\begin{abstract}
Effect of ethanol concentration variations on levels of polyphenols in the Biduri leaves extract (Calotropis gigantea L.), with the aim to determine the concentration of ethanol that produce high levels of polyphenols maximum on Biduri leaves extract (Calotropis gigantea L.). The method used in the form of laboratory experimental method, which leaves Biduri (Calotropis gigantea L.) is made in the form of extracts by using a variation of ethanol that is $50 \%$ ethanol, $70 \%$ and $96 \%$, then the variation of the extract polyphenols quantitative test conducted using standard gallat acid and Folin -ciocalteau reagen with UV-VIS spectrophotometry method. The results of quantitative analysis by UV-VIS spectrophotometry method at the maximum wavelength $730 \mathrm{~nm}$, obtained polyphenol content of $50 \%$ ethanol to extract $\mathrm{mgGAE}$ 11.14 / gram extract, $70 \%$ ethanol extract mg GAE 16.20 / gram extract, and 96\% ethanol extract 11, 72 mgGAE / gram of extract. Maximum levels of polyphenols contained in the ethanol extract with a concentration of $70 \%$. Based on statistical analysis, the results obtained polyphenol content of ethanol Biduri leaves extract (Calotropis gigantea L.) with the third variation of the concentration that is $50 \%, 70 \%$, and $96 \%$ were significantly different.
\end{abstract}

Keywords : Ethanol extract, Spectrophotometry UV-Vis, Total Polyphenols, Biduri leaves (Calotropis gigantea L.).

\section{PENDAHULUAN}

Sumber daya alam yang ada di Indonesia dari dulu sampai sekarang masih tetap kaya di mata dunia dan pada hakekatnya sumber daya ini bagi sebagian masyarakat Indonesia digunakan sebagai obat tradisional. Bangsa Indonesia sudah lama mengenal serta menggunakan tanaman obat berkhasiat sebagai salah satu upaya untuk menanggulangi masalah kesehatan. Pengetahuan tentang tanaman obat yang berkhasiat berdasar pada pengalaman yang telah diwariskan dari satu generasi ke generasi berikutnya. ${ }^{1}$

Perkembangan teknologi dan bentuk pemanfaatan tumbuhan obat di Indonesia dalam pelayanan kesehatan sudah mengenal serta menggunakan konsep ekstrak. Iptek kefarmasian 
Pengaruh variasi konsentrasi cairan penyari etanol terhadap kadar polifenol pada daun biduri (Calotropis gigantea L.)

telah berkembang pula pada bidang ekstraksi, sehingga dapat menerima ekstrak sebagai bentuk bahan yang dapat dipertanggungjawabkan mutu kandungan kimianya. $^{2}$

Salah satu yang digunakan sebagai obat tradisional adalah tanaman biduri (Calotropis gigantea L.). Biasanya tumbuh ditanah yang kurang subur, tersebar diberbagai daerah di Indonesia. Tumbuhan biduri (Calotropis gigantea L.) merupakan tanaman yang banyak dimanfaatkan sebagai pengobatan, bagian yang dimanfaatkan adalah bagian daun, batang, ataupun akarnya. Daunnya berkhasiat mengobati kudis, luka, borok, sariawan, gatal pada cacar air (varicella), campak (measles), deman, batuk, rubifisien dan menghilangkan gatal. Kandungan kimia pada daun diantaranya: flavonoid, polifenol, tannin, dan kalsium oksalat serta saponin. ${ }^{3}$

Polifenol adalah kelompok senyawa kimia yang diperoleh dari kulit, batang, akar, daun dan buah berbagai tanaman. ${ }^{4}$

Istilah senyawa fenol meliputi aneka ragam senyawa yang berasal dari tumbuhan yang mempunyai ciri sama yaitu cincin aromatik yang mengandung satu atau dua penyuluh hidroksil. Senyawa fenol cenderung mudah larut dalam air karena pada umumnya sering berikatan dengan gula sebagai glikosida, biasanya terdapat dalam vakuola sel. ${ }^{5}$

Polifenol merupakan senyawa turunan fenol yang mempunyai aktivitas sebagai antioksidan. Antioksidan fenolik biasanya digunakan untuk mencegah kerusakan akibat reaksi oksidasi pada makanan, kosmetik, dan farmasi. Fungsi polifenol sebagai penangkap dan pengikat radikal bebas dari rusaknya ion-ion logam. Kelompok tersebut sangat mudah larut dalam air dan lemak. ${ }^{6}$

Semua senyawa fenol berupa senyawa aromatik sehingga semuanya menunjukkan serapan kuat di daerah spektrum UV. Selain itu, secara khas senyawa fenol menunjukkan geseran batokrom pada spektrumnya ditambahkan basa. Karena itu, cara spektrofotomertri penting terutama untuk diidentifikasi dan analisis kuantitatif senyawa fenol. ${ }^{5}$

\section{METODE PENELITIAN}

\section{Alat-alat yang digunakan}

Alat yang digunakan yaitu batang pengaduk, aluminium foil,blender, corong buchner, cawan porselen, Erlenmeyer, gelas ukur, kertas saring whatman, labu ukur, mikropipet, pemanas listrik, seperangkat alat maserasi, 
Pengaruh variasi konsentrasi cairan penyari etanol terhadap kadar polifenol pada daun biduri (Calotropis gigantea L.)

seperangkat alat rotavapor, spektrofotometri UV-Vis, timbangan analitik.

\section{Bahan-bahan yang digunakan}

Bahan-bahan yang digunakan pada penelitian ini adalah: aquadest, asam galat, ekstrak daun biduri (Calotropis gigantea (L), etanol 50\%, etanol 70\%, etanol 96\%, Reagen Folin Ciocalteau, natrium karbonat.

Prosedur kerja

Pengambilan dan pengolahan sampel

Pengambilan sampel daun biduri (Calotropis gigantea (L.) dilakukan pada pagi hari sekitar pukul 08.00 - 10.00 WITA di kota Makassar, dengan cara mengambil daun yang masih segar secara manual, kemudian dibersihkan dari kotoran-kotoran yang menempel dengan menggunakan air yang mengalir dan dikeringkan pada suhu kamar dengan cara dianginanginkan tanpa terkena sinar matahari \pm 1 minggu. Setelah kering sampel dipotong-potong kecil dan diserbukkan menggunakan blender untuk memperoleh luas permukaan yang lebih besar agar proses penetrasi pelarut ke dalam bahan dapat berlangsung dengan optimal.

\section{Ekstraksi dengan pelarut etanol} Daun biduri (Calotropis
gigantea L.) di timbang masing 50 gram, kemudian dimaserasi menggunakan pelarut etanol $50 \%$, etanol $70 \%$ dan etanol $96 \%$, pada suhu ruang selama $3 \times 24$ jam, dan dimasukkan kedalam wadah yang tertutup rapat dan terlidung dari sinar matahari sambil diaduk. Hasil maserasi disaring, kemudian hasil penyarian tersebut masing-masing dikeringkan pada suhu kamar dengan cara dianging-anginkan hingga diperoleh ekstrak kering.

Pengukuran Kandungan Total Polifenol

Pembuatan Larutan Stok Natrium Karbonat 7\%

Ditimbang sebanyak 3.5 gram $\mathrm{Na} 2 \mathrm{CO} 3$ kemudian dilarutkan dengan aquades steril hingga $50 \mathrm{~mL}$

\section{Penetapan Kadar Fenolik Total}

Pembuatan larutan standar asam galat

Larutan standar asam galat 1000 ppm dibuat dengan menimbang $10 \mathrm{mg}$ asam galat, dilarutkan dengan etanol $96 \%$ hingga volume $10 \mathrm{~mL}$. Dari larutan stock dipipet sebanyak 0,25 $\mathrm{mL}$ diencerkan dengan etanol 96\% hingga volume $25 \mathrm{~mL}$ hingga dihasilkan konsentrasi 10 ppm kemudian di buat konsentrasi 1,2,3,dan 4 ppm.

Pengukuran sampel Daun Biduri (Calotropis gigantea L.) 
Pengaruh variasi konsentrasi cairan penyari etanol terhadap kadar polifenol pada daun biduri (Calotropis gigantea L.)

Penentuan Panjang Gelombang

Maksimal ( $\lambda$ maks)

Panjang gelombang maksimum asam galat dilakukan dengan merunning larutan asam galat $1 \mathrm{ppm}$ pada range panjang gelombang 710 $755 \mathrm{~nm}$. Absorbansi maksimum yang diperoleh pada panjang gelombang tertentu merupakan panjang gelombang maksimum asam galat.

Pengukuran larutan standar asam galat

Dipipet larutan asam galat masing-masing 1,2,3 dan $4 \mathrm{~mL}$ dari konsentrasi 10 ppm, lalu masingmasing ditambahkan dengan $0,4 \mathrm{~mL}$ reagen Folin-Ciocalteau dikocok dan dibiarkan 4-8 menit, tambahkan 4,0 $\mathrm{mL}$ larutan $\mathrm{Na} 2 \mathrm{CO} 3$ 7\% kocok hingg homogen. Tambahkan aquades hingga $10 \mathrm{~mL}$ dan diamkan selama 2 jam pada suhu ruangan. Ukur serapan pada panjang gelombang serapan maksimum $730 \mathrm{~nm}$, lalu dibuat kurva kalibrasinya, hubungan antara konsentrasi asam galat $(\mathrm{mg} / \mathrm{L})$ dengan absorbansi

Pembuatan larutan sampel ekstrak etanol daun biduri (Calotropis gigantea $\mathrm{L}$ )

Larutan ekstrak etanol 50\%, $70 \%$, dan $96 \%$ daun biduri (Calotropis gigantea L) dibuat dengan cara menimbang 10,0 mg ekstrak kemudian dilarutkan dengan $10 \mathrm{~mL}$ etanol $96 \%$.

Penetapan fenolik total ekstrak etanol daun biduri (Calotropis gigantea L)

Dipipet sebanyak $1 \mathrm{~mL}$ latutan ekstrak etanol $50 \%$ daun biduri (Calotropis gigantea L) , kemudian ditambahkan $0,4 \mathrm{~mL}$ reagen Folinciocalteau dikocok dan dibiarkan 4-8 menit, tambahkan 4,0 mL larutan Na2CO3 7\% kocok hingga homogeny. Tambahkan aquades hingga $10 \mathrm{~mL}$ dan diamkan selama 2 jam pada suhu ruangan. Ukur serapan pada panjang gelombang serapan maksimum 730 nm yang akan memberikan kompleks biru, dilakukan 3 kali pengulangan sehingga kadar fenolik yang diperoleh hasilnya didapat sebagai mg ekuivalen asam galat/g ekstrak. Perlakuan yang sama dilakukan untuk ekstrak etanol $70 \%$ dan ekstrak etanol $96 \%{ }^{6}$

\section{Pengumpulan Dan Analisis Data}

Analisis data terlebih dahulu dilakukan dengan metode kurva standar, regresi linear $\mathrm{y}=\mathrm{bx}+\mathrm{a}$ dibuat berdasarkan absorbansi dan konsentrasi dari larutan standar. 
Pengaruh variasi konsentrasi cairan penyari etanol terhadap kadar polifenol pada daun biduri (Calotropis gigantea L.)

\section{HASIL PENELITIAN}

Tabel 1. Hasil Pengukuran absorbansi larutan standar asam galat pada panjang gelombang $730 \mathrm{~nm}$.

\begin{tabular}{cc}
\hline Konsentrasi (ppm) & Absorbansi \\
\hline 1 & 0,087 \\
2 & 0,256 \\
3 & 0,489 \\
4 & 0,704 \\
\hline
\end{tabular}

Tabel 2. Hasil penetapan kadar fenol total \%(b/b) pada ekstrak etanol $50 \%, 70 \%$, dan $96 \%$ daun biduri (Calotropis gigantea L.).

\begin{tabular}{cccccc}
\hline Ekstrak & Rep. & $\begin{array}{c}\text { Absorbansi } \\
\text { (Y) }\end{array}$ & $\begin{array}{c}\text { Kandungan } \\
\text { polifenol awal } \\
\text { (mg/mL) }\end{array}$ & $\begin{array}{c}\text { Kandungan total } \\
\text { fenol } \\
\text { (mg GAE/g eks) }\end{array}$ & $\begin{array}{c}\text { Rata-rata } \\
\text { kandungan } \\
\text { fenol }\end{array}$ \\
\hline Etanol $50 \%$ & I & 0,112 & 1,197 & 11,97 & \\
& III & 0,088 & 1,082 & 10,82 & 11,140 \\
Etanol $70 \%$ & II & 0,084 & 1,063 & 10,63 & \\
& III & 0,217 & 1,702 & 17,02 & \\
Etanol $96 \%$ & II & 0,212 & 1,481 & 14,81 & 16,203 \\
& III & 0,107 & 1,678 & 16,78 & \\
\hline
\end{tabular}

\section{PEMBAHASAN}

Tumbuhan biduri (Calotropis gigantea L.) merupakan tanaman yang banyak dimanfaatkan sebagai pengobatan, bagian yang dimanfaatkan adalah bagian daun, batang, ataupun akarnya. Daunnya berkhasiat mengobati kudis, luka, borok, sariawan, gatal pada cacar air (varicella), campak (measles), deman, batuk, rubifisien dan menghilangkan gatal. Kandungan kimia pada daun diantaranya: flavonoid, polifenol, tannin, dan kalsium oksalat serta saponin.

Polifenol adalah fitonutrien, atau terkadang disebut sebagai fitokimia atau nutraseutikal, dan semakin banyak digunakan sebagai suplemen bahan makanan atau dalam makanan yang awet. Polifenol merupakan zat umum ditemukan dalam kingdom tanaman. ${ }^{4}$

Istilah senyawa fenol meliputi aneka ragam senyawa yang berasal dari tumbuhan yang mempunyai ciri sama yaitu cincin aromatik yang mengandung satu atau dua penyuluh hidroksil. Senyawa fenol cenderung mudah larut dalam air karena pada umumnya sering berikatan dengan gula sebagai glikosida, biasanya terdapat dalam vakuola sel. Ribuan senyawa fenolik di alam telah 
Pengaruh variasi konsentrasi cairan penyari etanol terhadap kadar polifenol pada daun biduri (Calotropis gigantea L.)

diketahui strukturnya antara lain flavanoid, fenol monosiklik sederhana, fenil propanoid, polifenol (pignin, melanin, tannin) dan kuinon fenolik. ${ }^{8}$

$$
\text { Metode ekstraksi yang }
$$

digunakan pada penelitian ini adalah maserasi. Dimana ekstraksi merupakan salah satu langkah awal dalam melakukan pembuatan ekstrak, metode ini juga sederhana, mudah dan tidak menggunakan proses pemanasan serta dilihat dari simplisia yang digunakan berupa daun yang memiliki tekstur lunak.

Keuntungan cara penyarian dengan maserasi adalah cara pengerjaan dan peralatan yang digunakan sederhana dan mudah diusahakan. Kerugian cara maserasi adalah pengerjaannya lama dan penyariannya kurang sempurna.

Penyarian dengan maserasi, diperlukan pengadukan untuk meratakan konsentrasi larutan di luar butir serbuk simplisia, sehingga dengan pengadukan tersebut tetap terjaga adanya derajat perbedaan konsentrasi yang sekecil-kecilnya antar larutan di dalam sel dengan larutan di luar sel. ${ }^{9}$

Dalam penelitian ini digunakan variasi konsentrasi pelarut etanol dengan Tujuan untuk menentukan konsentrasi etanol yang menghasilkan kadar polifenol yang maksimal pada ekstrak daun Biduri (Calotropis gigantea L.) Penetapan kandungan polifenol berdasarkan metode FolinCiocalteau (FC), yang merupakan metode yang paling umum digunakan untuk menentukan fenolik total. Dalam penelitian ini dipilih metode FolinCiocalteau $(F C)$ dengan pertimbangan bahwa teknik ini lebih mudah dan cara pengerjaannya sederhana. ${ }^{10}$

Untuk menentukan kadar senyawa polifenol pada sampel digunakan asam galat sebagai larutan standar. Digunakan asam galat sebagai larutan standar karena merupakan salah satu fenol alami yang memiliki efek antioksidan yang kuat. Dimana asam galat merupakan senyawa fenolik turunan dari asam hidroksibenzoat yang tergolong asam fenol sederhana. Tambahan pula, pilihan asam galat sebagai standar didasarkan atas ketersediaan substansi yang stabil dan lebih reaktif. ${ }^{11}$

Pereaksi Folin-Ciocalteau, mengoksidasi fenolat (garam alkali) atau gugus fenolik-hidroksi mereduksi asam heteropoli (fosfomolibdatfosfotungstat)yang terdapat dalam pereaksi Folin-Ciocalteau menjadi suatu kompleks molybdenumtungsten. Senyawa fenolik bereaksi 
Pengaruh variasi konsentrasi cairan penyari etanol terhadap kadar polifenol pada daun biduri (Calotropis gigantea L.)

dengan reagen Folin-Ciocalteau hanya dalam suasana basa agar terjadi disosiasi proton pada senyawa fenolik menjadi ion fenolat. Untuk menciptakan kondisi basa digunakan $\mathrm{Na}_{2} \mathrm{CO}_{3} \quad 7 \%$, selama reaksi berlangsung, gugus hidroksil pada senyawa fenolik bereaksi dengan pereaksi Folin-Ciocalteau, membentuk kompleks molybdenum-tungsten berwarna biru dan dapat dideteksi dengan spektrofotometer. Warna biru yang terbentuk akan semakin pekat, setara dengan konsentrasi ion fenolat yang terbentuk, artinya semakin besar konsentrasi senyawa fenolik maka semakin banyak ion fenolat yang akan mereduksi asam heteropoli (fosfomolibdat fosfotungstat) menjadi kompleks molibdenum-tungsten sehingga warna biru yang dihasilkan semakin pekat. $^{12}$

Pada saat penambahan pereaksi terjadi pergeseran merah atau efek batokromik yang dimana merupakan pergeseran serapan maksimum ke panjang gelombang yang lebih panjang. Hal ini dapat disebabkan oleh perubahan pelarut atau adanya suatu auksokrom, bertambah besarnya panjang gelombang pada senyawa fenolik sehingga dapat diukur di daerah visible.
Asam galat direaksikan dengan reagen Folin-Ciocalteau akan menghasilkan warna kuning yang menandakan bahwa mengandung fenol, setelah itu ditambahkan dengan larutan $\mathrm{Na}_{2} \mathrm{CO}_{3}$ menghasilkan warna biru. Intensitas warna biru ditentukan dengan banyaknya kandungan fenol dalam larutan sampel, semakin besar konsentrasi senyawa fenolik dalam sampel semakin pekat warna biru yang terlihat, penambahan $\mathrm{Na}_{2} \mathrm{CO}_{3}$ pada uji fenolik bertujuan untuk membentuk suasana basa agar terjadi reaksi reduksi Folin-Ciocalteau oleh gugus hidroksil dari fenolik di dalam sampel. ${ }^{13}$

Pada pengukuran senyawa polifenol pada sampel ekstrak etanol $50 \%$, sampel ditimbang sebanyak 10 mg dilarutkan dalam $10 \mathrm{~mL}$ etanol $96 \%$, di pipet $1 \mathrm{~mL}$ dan ditambahkan $0,4 \mathrm{~mL}$ reagen folin-ciocalteau, kemudian didiamkan selama 8 menit, kemudian ditambah $4 \mathrm{~mL} \mathrm{Na} \mathrm{CO}_{3} 7 \%$ dan dicukupkan dengan aquades hinggal $10 \mathrm{~mL}$ sehingga didapatkan larutan ekstrak etanol $50 \%$ berwarna biru bening, di inkubasi selama 2 jam dan diukur absorbansi larutan pada serapan maksimum $730 \mathrm{~nm}$ dengan spektrofotometri UV-VIS, dan didapatkan absoebansi dari sampel, lalu diplotkan nilai absorbansi sampel 
Pengaruh variasi konsentrasi cairan penyari etanol terhadap kadar polifenol pada daun biduri (Calotropis gigantea L.)

kedalam persamaan garis linear yang dihasilkan pada pengukuran larutan standar asam galat. Perlakuan yang sama dilakukan untuk ekstrak etanol $70 \%$ dan ekstrak etanol $96 \%$.

Hasil pengukuran absorbansi larutan standar asam galat yang diperoleh dimasukkan ke dalam Microsoft excel untuk mendapatkan kurva kalibrasi larutan standar asam galat berupa grafik kurva konsentrasi (C) versus absorbansi(A). Berdasarkan gambar dapat dilihat bahwa kurva kalibrasi dengan persamaan regresi untuk absorbansi asam galat yaitu sebesar $y=0,208 x-$ 0,137 ; larutan standar senyawa polifenol diperoleh, hubungan yang linear antara absorbansi dengan konsentrasi. Pada pengukuran absorbansi yang ditunjukkan dengan nilai koefisisen korelasi ( $r$ ) sebesar 0,996, nilai $(r)$ ini mendekati angka 1 yang menunjukkan bahwa persamaan regresi tersebut adalah linier.

Persamaan kurva tersebut dapat digunakan sebagai pembanding untuk menentukan konsentrasi senyawa polifenol yang terdapat pada ekstrak etanol 50\%,70\% dan $96 \%$. Pada penelitian ini kandungan polifenol ditentukan berdasarkan penentuan absorbansi sampel dimana untuk ekstrak etanol $50 \%$ yang diperoleh dari tiga kali pengukuran yaitu 0,$112 ; 0,088 ;$ dan 0,084 , sedangkan untuk ekstrak etanol $70 \%$ yang diperoleh 0,$217 ; 0,171$; dan 0,212 . Selanjutnya untuk ekstrak etanol $96 \%$ diperoleh absorbansi 0,104; 0,107 dan 0, 109. Dari nilai absorbansi dapat diketahui nilai konsetrasi polifenol yang terdapat pada ekstrak etanol daun biduri (Calotropis gigantea L.) dengan menggunakan persamaan regresi liniear dari kurva konsentrasi standar asam galat. Hasil analisis kuantitatif berdasarkan metode spektrofotometri UV-Vis pada panjang gelombang maksimum $730 \mathrm{~nm}$, diperoleh kadar polifenol untuk ekstrak etanol $50 \%$ adalah $1,114 \%$ atau setara dengan 11,14 mgGAE/gram ekstrak. Untuk ekstrak etanol $70 \%$ diperoleh $1,62 \%$ atau setara dengan 16,20 mgGAE/gram ekstrak, sedangkan untuk ekstrak etanol 96\% diperoleh kandungan polifenol $1,172 \%$ atau setara dengan 11,72 mgGAE/gram ekstrak. Kadar senyawa polifenol ditunjukkan dalam GAE(gallat acid ekuivalen) karena belum diketahui struktur kimia senyawa polifenol yang terdapat dalam daun biduri(Calotropis gigantean L.)

Berdasarkan analisis statistik, didapatkan hasil kadar polifenol 
Pengaruh variasi konsentrasi cairan penyari etanol terhadap kadar polifenol pada daun biduri (Calotropis gigantea L.)

ekstrak etanol daun Biduri (Calotropis gigantea L.) dengan ketiga variasi konsentrasi yaitu $50 \%, 70 \%$, dan $96 \%$ berbeda nyata.

\section{KESIMPULAN}

Dari hasil penelitian ini, maka dapat disimpulkan bahwa variasi konsentrasi cairan etanol dapat mempengaruhi kadar total polifenol. Kadar polifenol yang maksimal pada ekstrak daun Biduri (Calotropis gigantea L.) adalah ekstrak etanol dengan konsentrasi $70 \%$ yaitu $1,62 \%$ atau setara dengan 16,20 mgGAE/gram ekstrak. Berdasarkan analisis statistik, didapatkan hasil kadar polifenol ekstrak etanol daun Biduri (Calotropis gigantea L.) dengan ketiga variasi konsentrasi yaitu $50 \%$, $70 \%$, dan $96 \%$ berbeda nyata.

\section{DAFTAR PUSTAKA}

1. Pujiade WA. Etnofarmasi Tumbuhan Obat Asal Kabupaten Soppeng Provinsi Sulawesi Selatan (Skripsi). Makassar : Universitas Muslim Indonesia, 2011.

2. Direktoral Jenderal Pengawasan Obat dan Makanan. Parameter Standar Umum Ekstrak Tumbuhan Obat. Jakarta : Departemen Kesehatan RI, 2000.

3. Nio OK. Zat-Zat Toksik yang Secara Alamiah Ada pada Bahan Makanan Nabati. Cermin Dunia Kedokteran 1989; 58(24).
4. Mazdink. Polifenol dan Tannin Pada Minuman Bir, Anggur, dan Coklat.

(http./polifenol/Penerjemahonlineln ggris-Indonesia.htm) diakses 5 Maret 2014). Jakarta; 2008.

5. Harbone JB. Metode fitokimia : Penuntun Cara Modern Menganalisa Tumbuhan. Terbitan Kedua. Terjemahan Kosasih Padmawinata dan Iwang Soediro. Bandung : Institut Tehnologi Bandung, 1987.

6. Ganiswara. Farmakologi dan Terapi. Jakarta : Badan Farmakologi Fakultas Kedokteran UI, 1995.

7. Andayani R, dkk. Penentuan Aktivitas Antioksidan, Kadar Fenolat Total dan Likopen Pada Buah Tomat. Jurnal Sains dan Teknologi, 2008.

8. Fauziah L. Studi dimerisasi asam ferulat dan esternya melalui reaksi oksidatif kopling dengan biokatalis peroksidase (skripsi). Depok : F MIPA UI, 2008.

9. Direktorat Jenderal Pengawasan Obat dan Makanan. Sediaan Galenik. Jakarta : Departemen Kesehatan Republik Indonesia, 1986.

10. Mariska PV. Pengujian Kandungan Fenol Total Tomat (Lycopersicum esculentum) secara in vitro (Skripsi). Jakarta : Fakultas Kedokteran UI, 2009.

11. Rahmawati A. Kandungan Fenol Total Ekstrak Buah Mengkudu (Skripsi). Jakarta : Fakultas Kedokteran UI, 2009. 
Pengaruh variasi konsentrasi cairan penyari etanol terhadap kadar polifenol pada daun biduri (Calotropis gigantea L.)

12. Aspari PD, Susanti $H$. Perbandingan Kadar Fenolik Total Ekstrak Metanol Kelopak Merah dan Ungu Bunga Rosella (Hibiscus sabdariffa Linn) Secara Spektrofotometri, 2011.
13. Ismail J, Runtuwene M, Fatimah F. Penentuan Total Fenolik Dan Uji Aktivitas Antioksidan Pada Biji dan Kulit Buah Pinang Yaki (Areca vestiaria Giseke). 2012. 